\title{
Wild-Type Human TDP-43 Expression Causes TDP-43 Phosphorylation, Mitochondrial Aggregation, Motor Deficits, and Early Mortality in Transgenic Mice
}

\author{
Ya-Fei Xu, ${ }^{1}$ Tania F. Gendron, ${ }^{1}$ Yong-Jie Zhang, ${ }^{1}$ Wen-Lang Lin, ${ }^{1}$ Simon D’Alton, ${ }^{1}$ Hong Sheng, ${ }^{1}$ \\ Monica Castanedes Casey, ${ }^{1}$ Jimei Tong, ${ }^{1}$ Joshua Knight, ${ }^{1}$ Xin Yu, ${ }^{1}$ Rosa Rademakers, ${ }^{1}$ Kevin Boylan, ${ }^{2}$ \\ Mike Hutton, ${ }^{1}$ Eileen McGowan, ${ }^{1}$ Dennis W. Dickson, ${ }^{1}$ Jada Lewis, ${ }^{1}$ and Leonard Petrucelli ${ }^{1}$ \\ Departments of ${ }^{1}$ Neuroscience and ${ }^{2}$ Neurology, Mayo Clinic, Jacksonville, Florida 32224
}

\begin{abstract}
Transactivation response DNA-binding protein 43 (TDP-43) is a principal component of ubiquitinated inclusions in frontotemporal lobar degeneration with ubiquitin-positive inclusions and in amyotrophic lateral sclerosis (ALS). Mutations in TARDBP, the gene encoding TDP-43, are associated with sporadic and familial ALS, yet multiple neurodegenerative diseases exhibit TDP-43 pathology without known TARDBP mutations. While TDP-43 has been ascribed a number of roles in normal biology, including mRNA splicing and transcription regulation, elucidating disease mechanisms associated with this protein is hindered by the lack of models to dissect such functions. We have generated transgenic (TDP- $43_{\mathrm{PrP}}$ ) mice expressing full-length human TDP-43 (hTDP-43) driven by the mouse prion promoter to provide a tool to analyze the role of wild-type hTDP-43 in the brain and spinal cord. Expression of hTDP-43 caused a dose-dependent downregulation of mouse TDP-43 RNA and protein. Moderate overexpression of hTDP-43 resulted in TDP-43 truncation, increased cytoplasmic and nuclear ubiquitin levels, and intranuclear and cytoplasmic aggregates that were immunopositive for phosphorylated TDP-43. Of note, abnormal juxtanuclear aggregates of mitochondria were observed, accompanied by enhanced levels of Fis1 and phosphorylated DLP1, key components of the mitochondrial fission machinery. Conversely, a marked reduction in mitofusin 1 expression, which plays an essential role in mitochondrial fusion, was observed in TDP- $43_{\operatorname{PrP}}$ mice. Finally, TDP- $43_{\operatorname{PrP}}$ mice showed reactive gliosis, axonal and myelin degeneration, gait abnormalities, and early lethality. This TDP- 43 transgenic line provides a valuable tool for identifying potential roles of wild-type TDP-43 within the CNS and for studying TDP-43-associated neurotoxicity.
\end{abstract}

\section{Introduction}

The transactivation response DNA-binding protein 43 (TDP-43) is the primary component of ubiquitinated inclusions in most cases of amyotrophic lateral sclerosis (ALS) and frontotemporal lobar degeneration with ubiquitin-positive inclusions (FTLD-U) (Arai et al., 2006; Neumann et al., 2006). Mutations in TARDBP, the gene encoding TDP-43, are associated with sporadic and familial ALS (Gitcho et al., 2008; Kabashi et al., 2008; Rutherford et al., 2008; Sreedharan et al., 2008; Yokoseki et al., 2008), indicating that alteration of TDP-43 can directly cause neurodegeneration.

In TDP-43 proteinopathies, TDP-43 is hyperphosphorylated and N-terminally truncated (Arai et al., 2006; Neumann et al.,

Received March 30, 2010; revised May 26, 2010; accepted June 21, 2010.

This work was supported by the Mayo Clinic Foundation, Amyotrophic Lateral Sclerosis Association Milton Safenowitz Postdoctoral Fellowship (T.F.G.), American Federation for Aging Research Affiliate Research Grant Program (Y.Z.), Pacific Alzheimer Research Foundation (R.R.), Association for Frontotemporal Dementias (R.R.), National Institutes of Health/National Institute on Aging [P50AG16574 (D.W.D., R.R., E.M.); R01AG026251 and 2R56AG026251-03A1 (L.P.); and P01-AG17216-08 (L.P., D.W.D.)], National Institutes of Health/National Institute of Neurological Disorders and Stroke [R01 NS $063964-01$ (L.P.)], Amyotrophic Lateral Sclerosis Association (L.P. and J.L.), and Department of Defense [USAMRMC PR080354 (L.P. and J.L.)].

Y.-F.X., Y.-J.Z., M.H., E.M., J.L., and L.P. are inventors of this and related mouse models.

Correspondence should be addressed to Dr. Jada Lewis, Department of Neuroscience, Mayo Clinic, 4500 San Pablo Road, Jacksonville, FL 32224. E-mail: lewis.jada@mayo.edu.

DOI:10.1523/JNEUROSCI.1630-10.2010

Copyright $\odot 2010$ the authors $\quad$ 0270-6474/10/3010851-09\$15.00/0
2006). Phosphorylated TDP-43 is detected in many inclusions, like dystrophic neurites, cytoplasmic inclusions, and intranuclear inclusions (Hasegawa et al., 2008; Neumann et al., 2009). Of note, the cytoplasmic deposition of TDP-43 is associated with loss of TDP-43 immunoreactivity in the nucleus, where it is normally located (Arai et al., 2006; Neumann et al., 2006). The mechanism through which TDP-43 mediates neuronal death remains unclear, though it may be attributable to both toxic gain and loss of functions caused by posttranslational modifications, aggregate formation, and sequestration of normal TDP-43.

The gaps in our knowledge regarding TDP-43 function and dysfunction, and how TDP-43 contributes to neurodegeneration, will surely narrow as TDP-43 models continue to emerge. For example, Wils et al. (2010) generated mice overexpressing wild-type human TDP-43 (hTDP-43) under the control of a neuronal murine Thy-1 promoter. Degeneration of cortical and spinal motor neurons, accompanied by spastic quadriplegia, was observed in these mice. Affected neurons showed nuclear and cytoplasmic TDP-43 aggregates that were ubiquitinated and phosphorylated (Wils et al., 2010). Interestingly, a second TDP-43 mouse model suggests that TDP-43-mediated toxicity does not require the formation of TDP-43 aggregates. To elucidate the involvement of mutant TDP-43 in neurodegeneration, Wegorzewska et al. (2009) generated transgenic mice expressing A315T hTDP-43 under the control of the mouse prion protein 
(PrP) promoter. Ubiquitin-positive, but TDP-43-negative, aggregates accumulated in specific neuronal populations of $\mathrm{PrP}-$ TDP43 ${ }^{\mathrm{A} 315 \mathrm{~T}}$ mice and fatal neurodegeneration was observed. Since a control wild-type hTDP-43 line was not included in that study (Wegorzewska et al., 2009), it is difficult to definitively ascribe the phenotype of Prp-TDP43 ${ }^{\mathrm{A} 315 \mathrm{~T}}$ mice to mutant hTDP-43 rather than to TDP-43 overexpression in general. To expand the current understanding of TDP-43 function, and to provide an essential resource to dissect the pathogenic mechanisms between wild-type and mutant hTDP-43, we generated transgenic (TDP- $43_{\mathrm{PrP}}$ ) mice expressing wild-type hTDP-43 under the control of the PrP promoter.

In TDP- $43_{\text {PrP }}$ mice, hTDP-43 is expressed in the brain and spinal cord, regions relevant to TDP-43 proteinopathies, which causes a dose-dependent downregulation of mouse TDP-43 (mTDP-43). TDP-43 $3_{\operatorname{PrP}}$ mice recapitulate certain features of ALS, such as TDP-43 cleavage, phosphorylation, and aggregation, gait disturbances, and early lethality. Importantly, there is evidence of impaired mitochondrial dynamics, resulting in the accumulation of clusters of abnormal mitochondria within neurons. The fundamental importance of this model, in combination with other animal models, will be in expanding our understanding of TDP-43 function and elucidating novel targets for its normal regulatory roles.

\section{Materials and Methods}

Generation of TDP $-43_{\text {PrP }}$ transgenic mice. To generate TDP $-43_{\operatorname{PrP}}$ mice, total RNA was extracted from human brain with the RNeasy Plus Mini Kit (Qiagen) and reverse transcribed into hTDP-43 cDNA using the following primers: 5' -TTAACTCGAGCTTCCCAGCAGCGGCCTAG-3' and 5' -TAATCTCGAGACCAACCAACCACAACCCCAC-3'. hTDP-43 cDNA, containing $\sim 35 \mathrm{bp}$ of the $5^{\prime}$ UTR and $24 \mathrm{bp}$ of the $3^{\prime} \mathrm{UTR}$ was inserted into the XhoI site of the MoPrP vector (Borchelt et al., 1996). Following sequencing, the construct was linearized with NotI, gel purified, and digested with $\beta$-agarose. DNA was filtered, concentrated, and diluted to $3 \mathrm{ng} / \mu \mathrm{l}$ in microinjection buffer. The transgene was microinjected into fertilized C57BL/6 (B6) mouse eggs and reimplanted into pseudopregnant females. Six founders were mated with B6 mice, and the TDP- $43_{\operatorname{PrP}}$ founder line with the highest level of expression (2.5-fold in homozygotes compared to endogenous TDP-43 levels) was used for all subsequent experiments. Procedures were performed in accordance with the Mayo Institutional Animal Care and Use Committee.

Genotyping. Transgenic mice were identified by PCR using hTDP43-specific primers: 5'-TGGAGAAGTTCTTATGGTGCAGGTC-3' and $5^{\prime}$-GGTATTAGCCTATGGGGGACAC-3' against control actinspecific primers (5' -CGGAACCGCTCATTGCC-3' and $5^{\prime}$-ACCCACACTGTGCCCATCTA-3').

Quantitative real-time PCR. Levels of human and mouse TDP-43 transcripts were determined via TaqMan Gene Expression Assays (Applied Biosystems). Total RNA was isolated from tail samples using TRIzol (Invitrogen) and Pure Link RNA Mini Kit (Invitrogen), and $3 \mu \mathrm{g}$ were used to synthesize cDNA using the High Capacity cDNA Reverse Transcription Kit (Applied Biosystems). The qPCR assay used the following: hTDP-43 Hs00606522_m1, mTDP-43 Mm00523866_m, and 18S rRNA Hs99999901_s1. The PCR was run on the ABI 7900 and data analyzed using Software RQ Manager 1.2 (Applied Biosystems).

Tissue preparation. Sagittal half brain and spinal column were immersion fixed in $10 \%$ formalin for immunohistochemistry, and the other half brain was frozen on dry ice for biochemistry. After $24 \mathrm{~h}$, the spinal cord was removed from the vertebral column and fixed overnight.

Western blotting. Tissues were homogenized at $10 \mathrm{ml} / \mathrm{g}$ (volume/ weight) in lysis buffer (50 mm Tris- $\mathrm{HCl}, \mathrm{pH} 7.4,300 \mathrm{~mm} \mathrm{NaCl}, 1 \%$ Triton $\mathrm{X}-100,5 \mathrm{~mm}$ EDTA, 2\% SDS, PMSF, and protease and phosphatase inhibitor). Following centrifugation, supernatant was assessed by BCA assay (Pierce). Following Western blotting, membranes were incubated with the following: mouse monoclonal TDP-43 antibody (1:1000, 2E2-
D3, Novus Biologicals) which was generated using amino acids 1-261 of hTDP-43 as the immunogen and was found to recognize amino acids 205-222 of human TDP-43 by epitope mapping (Zhang et al., 2008); rabbit polyclonal TDP-43 antibody against amino acids 1-260 (1:1000; ProteinTech Group, 10782-2-AP); rabbit polyclonal C-terminal TDP-43 antibody against amino acids 260-414 (1:1000; ProteinTech Group, 12892-1-AP); mouse monoclonal glyceraldehyde-3-phosphate dehydrogenase (GAPDH) antibody (1:10,000; Biodesign International); mouse DLP1 antibody (BD Transduction Laboratories); rabbit phospho-DLP1 (Ser616) antibody (Cell Signaling); rabbit Fis1 antibody (IMGENEX); or mouse mitofusin 1 antibody (Novus Biologicals). Following incubation with an appropriate secondary antibody, immunoreactivity was visualized by ECL and exposure to film.

Immunohistochemistry and histochemistry. Tissues were embedded in paraffin, sectioned ( $5 \mu \mathrm{m}$ thick), and mounted on glass slides. Sections were deparaffinized in xylene and rehydrated in a graded series of alcohol, followed by $\mathrm{dH}_{2} \mathrm{O}$. Antigen retrieval was performed in a $\mathrm{dH}_{2} \mathrm{O}$ steam bath for $30 \mathrm{~min}$. Tissues were immunostained with monoclonal TDP-43 antibody (1:3000; Novus Biologicals) or antibodies toward pS403/S404phosphorylated TDP-43 (1:2000; Cosmo Bio), ubiquitin (1:60,000; Millipore Bioscience Research Reagents), glial fibrillary acidic protein (GFAP; 1:2500; Biogenex), ionized calcium-binding adaptor molecule 1 (IBA-1; 1:2000; Wako Chemicals), or cytochrome oxidase subunit IV (COX-IV; 1:3000; Abcam) using the DAKO Autostainer (Dako Auto Machine Corporation) and the DAKO EnVision + HRP system. DAKO Liquid DAB Substrate-Chromogen system was the chromogen. pTDP-43 antibody slides were dehydrated and counterstained with either hematoxylin or eosin. Silver staining was performed using the FD NeuroSilver Kit II (FD Neurotech). Paraffin-embedded sections were also stained for the toluidine blue staining and hematoxylin and eosin. Luxol fast blue/periodic acid Schiff (LFB/PAS) staining was performed as previously described (Lin et al., 2005).

Immunofluorescence staining. Paraffin sections of mouse spinal cord (5 $\mu \mathrm{m})$ were deparaffinized and rehydrated in xylene and a graded series of alcohol $(100,100,95$, and 70\%). After blocking with 5\% BSA for $1 \mathrm{~h}$ at $37^{\circ} \mathrm{C}$, the sections were incubated overnight at $4^{\circ} \mathrm{C}$ with mouse monoclonal TDP-43 antibody (1:200, 2ED-D3, Novus Biologicals) and rabbit polyclonal ubiquitin antibody (1:100, DakoCytomation). After washing, sections were incubated with the Alexa 568 Oregon Green-conjugated goat anti-mouse IgG secondary antibody (1:500, Invitrogen) or Oregon Green 488-conjugated goat anti-rabbit IgG secondary antibody (1:500, Invitrogen $)$ at $37^{\circ} \mathrm{C}$ for $2 \mathrm{~h}$. Finally, Hoechst $33258(1 \mu \mathrm{g} / \mathrm{ml}$, Invitrogen $)$ was used to stain the nuclei. Images were obtained on a Zeiss LSM 510 META confocal microscope.

Electron microscopy. Spinal cords from 4\%-paraformaldehydeperfused mice were immersed in $2.5 \%$ glutaraldehyde- $0.1 \mathrm{M}$ cacodylate buffer, postfixed in $1 \% \mathrm{OsO}_{4}$, dehydrated in alcohol and propylene oxide, and finally infiltrated and embedded in Epon 812. Ultrathin sections mounted on copper grids were stained with uranyl acetate and lead citrate. Images were obtained with a Gatan CCD camera using a Philips 208 S electron microscope.

Gait analysis methods. Swing and stance components of stride were captured by the DigiGait system (Mouse Specifics). Mice were placed on the transparent motorized treadmill belt that rotated at $10 \mathrm{~cm} / \mathrm{s}$. A camera captured the feet and corresponding limb movement from the ventral side of the mice. The DigiGait software calculated spatial and temporal gait indices which were used to determine gait abnormalities between transgenic and nontransgenic (NT) mice.

\section{Results \\ hTDP-43 expression, gait disturbances, and early lethality in TDP $-43_{\text {PrP }}$ mice}

To study the normal function of hTDP-43 and its role in neurodegeneration, we generated transgenic mice using the mouse PrP promoter (Borchelt et al., 1996) to drive expression of full-length, wild-type hTDP-43 from a TARDBP cDNA. Four of six TDP$43_{\operatorname{PrP}}$ founders showed germline transmission, and we focused on the line with the highest expression. Immunohistochemistry 


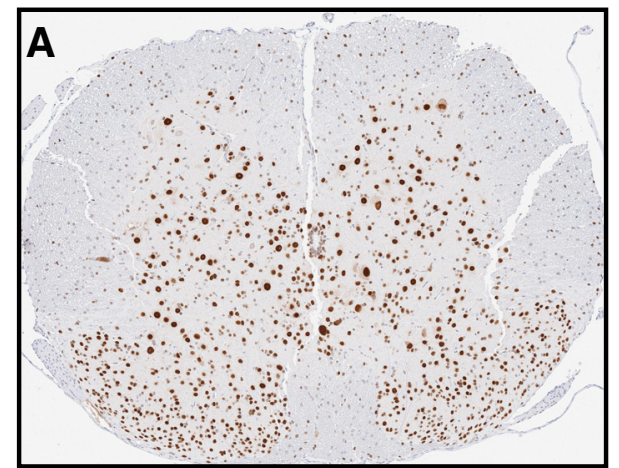

C

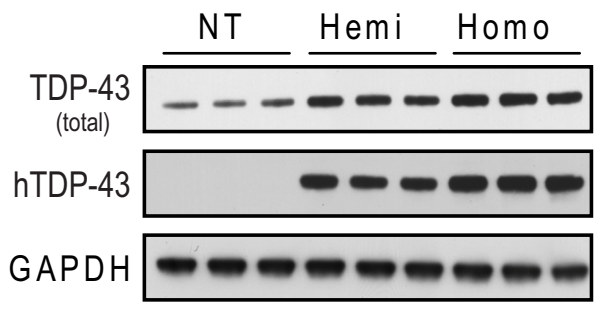

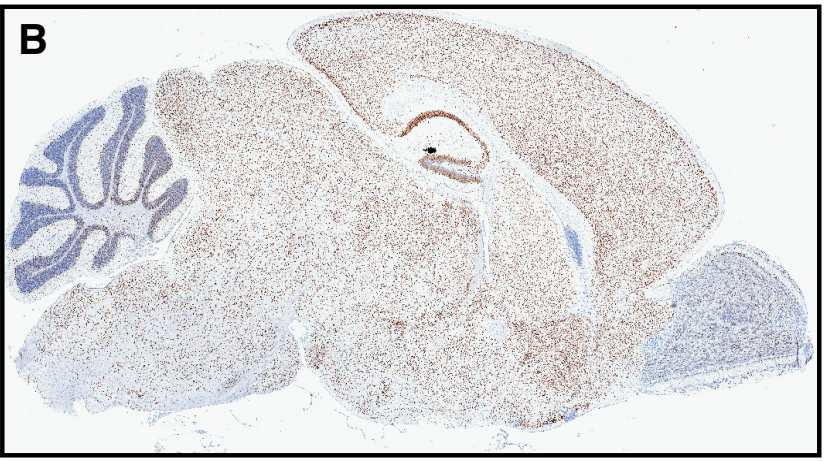

D
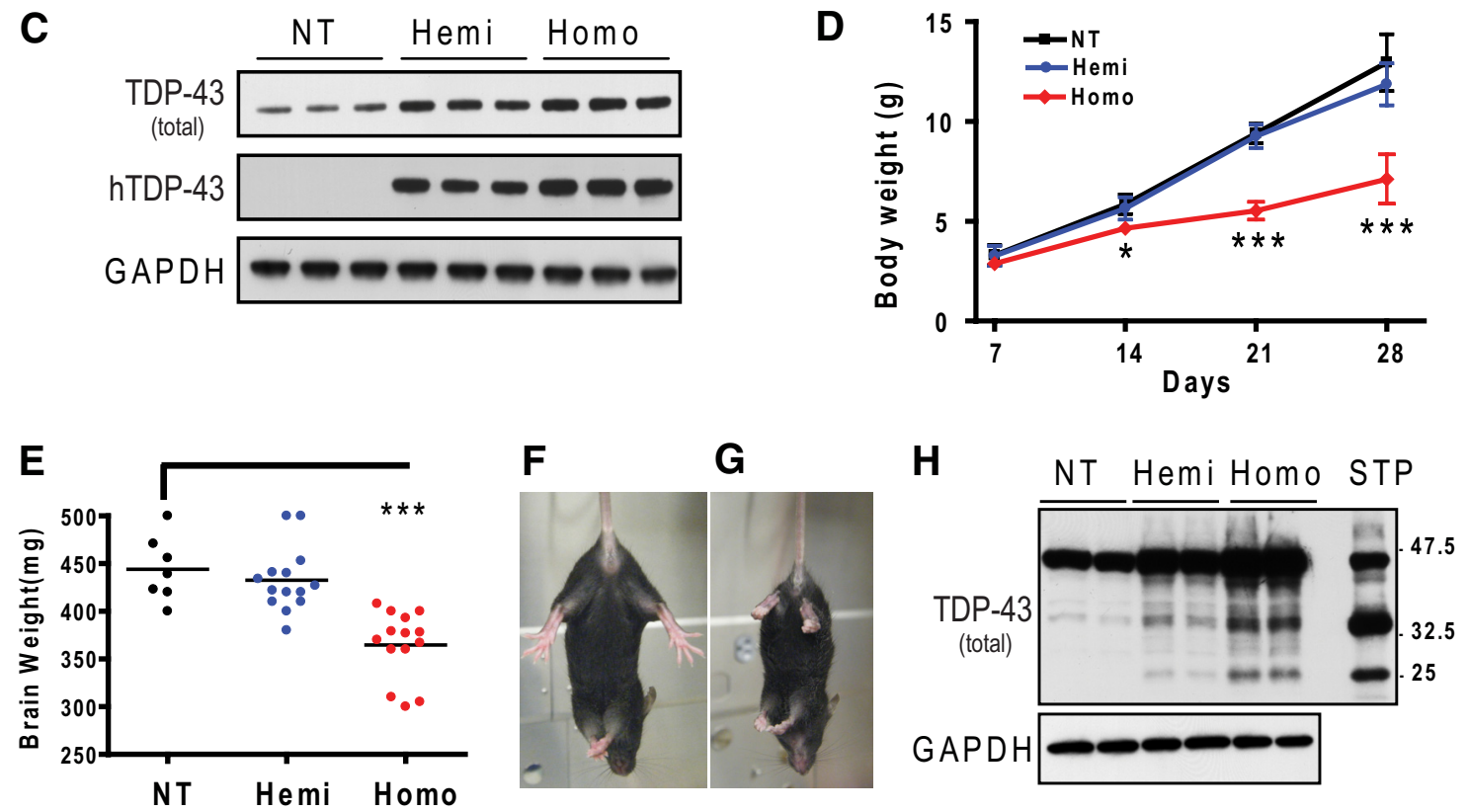

Figure 1. TDP-43 $3_{\text {PrP }}$ mice expressing hTDP-43 in the brain and spinal cord display reduced brain and body weight and abnormal escape response. $\boldsymbol{A}, \boldsymbol{B}$, Immunohistochemistry shows $h$ TDP-43 distributed throughout the gray matter of the spinal cord $(\boldsymbol{A})$ and brain $(\boldsymbol{B})$ in homozygous TDP-43 $3_{\mathrm{PrP}}$ mice. $\boldsymbol{C}$, Western blots of brain lysates from NT, as well as hemizygous and homozygous TDP-43 PrP mice using antibodies that detect either both mTDP-43 and hTDP-43 (total TDP-43) or hTDP-43 only. GAPDH immunoreactivity was included to ensure equal loading. D, Compared to NT and hemizygous mice, homozygous TDP-43 ${ }_{\text {Prp }}$ mice had significant deficits in body weight. By $28 \mathrm{~d}$, the average body weight of homozygous TDP-43 ${ }_{\text {Prp }}$ mice was approximately half that of controls. Data shown are the means \pm SEM of 8 mice per group; ${ }^{*} p<0.05,{ }^{* * *} p<0.001$, as assessed by two-way ANOVA followed by Bonferroni post hoc test. $E$, At 1 month, brain weight of homozygous TDP-43 PrP mice was significantly lower than that of age-matched NT and hemizygous mice. Data shown are the means of 7-14 mice per group. ${ }^{* * *} p<0.001$, as assessed by one-way AN0VA. $\boldsymbol{F}$, $\boldsymbol{G}$, Upon tail elevation, homozygous mice ( $\boldsymbol{G}$ ) held their hindlimbs close to their body and failed to show proper escape extension, while NT mice $(\boldsymbol{F})$ showed normal escape response by splaying their hindlimbs. $\boldsymbol{H}$, Immunoblot of spinal cord lysates from NT, hemizygous and homozygous TDP-43 ${ }_{\text {PrP }}$ mice using an antibody that detects total TDP-43. Note that TDP-43 fragments ( $\sim 35$ kDa and 25 $\mathrm{kDa}$ ) in spinal cord comigrate with (-terminal fragments generated by staurosporine (STP)-induced caspase activation in human neuroglioma cells expressing hTDP-43. hemi, Hemizygous; homo, homozygous.

(IHC) of brain and spinal cord of mice from this line using a human-specific TDP-43 antibody (Abnova, 2E2-D3) revealed hTDP-43 expression primarily in nuclei of neurons and distributed throughout much of the gray matter of the spinal cord and brain, including the hippocampus, striatum, brainstem, and cortex, particularly in layers II-VI of the latter (Fig. $1 A, B$ ). Biochemical analysis of hTDP-43 in homozygous TDP- $43_{\operatorname{PrP}}$ mice showed that protein expression was highest in the brain and spinal cord, with moderate levels in the testis and spleen, and low levels in other tissues, such as the heart, liver, and kidneys (supplemental Fig. $1 A$, available at www.jneurosci.org as supplemental material). Based on Western blot analysis of brain lysates using a TDP-43 antibody (ProteinTech Group, 10782-2-AP) that detects both hTDP-43 and mTDP-43, hemizygous and homozygous mice expressed TDP-43 at 1.9- and 2.5-fold endogenous levels, respectively (Fig. $1 C$; supplemental Fig. $1 B$, available at www. jneurosci.org as supplemental material $)(p<0.01, n=3)$. These results indicate that total TDP-43 expression in homozygotes was $\sim 31 \%$ higher than in hemizygotes. Yet, when hTDP-43 levels were assessed with an hTDP-43-specific antibody, it was found that hTDP-43 levels were $\sim 76 \%(p<0.001 ; n=3)$ higher in homozygotes compared to hemizygotes (Fig. 1C; supplemental Fig. $1 C$, available at www.jneurosci.org as supplemental material). Given this discrepancy, mTDP-43 and hTDP-43 RNA levels were quantified by real time-PCR. As expected, hTDP-43 RNA expression was 2.1-fold higher in homozygotes compared to hemizygotes in spinal cord and cortex $(p<0.001$ both regions; $n=3$, data not shown). In contrast, mTDP-43 RNA in TDP$43_{\mathrm{PrP}}$ mice was significantly decreased in both the cortex and spinal cord compared to NT mice. In the spinal cord, mTDP-43 mRNA levels were decreased by $73 \%(p<0.05, n=3)$ and $68 \%$ $(p<0.01, n=3)$ in hemizygous and homozygous mice, respectively, compared to NT mice (supplemental Fig. $1 D$, available at www.jneurosci.org as supplemental material). In the cortex, 

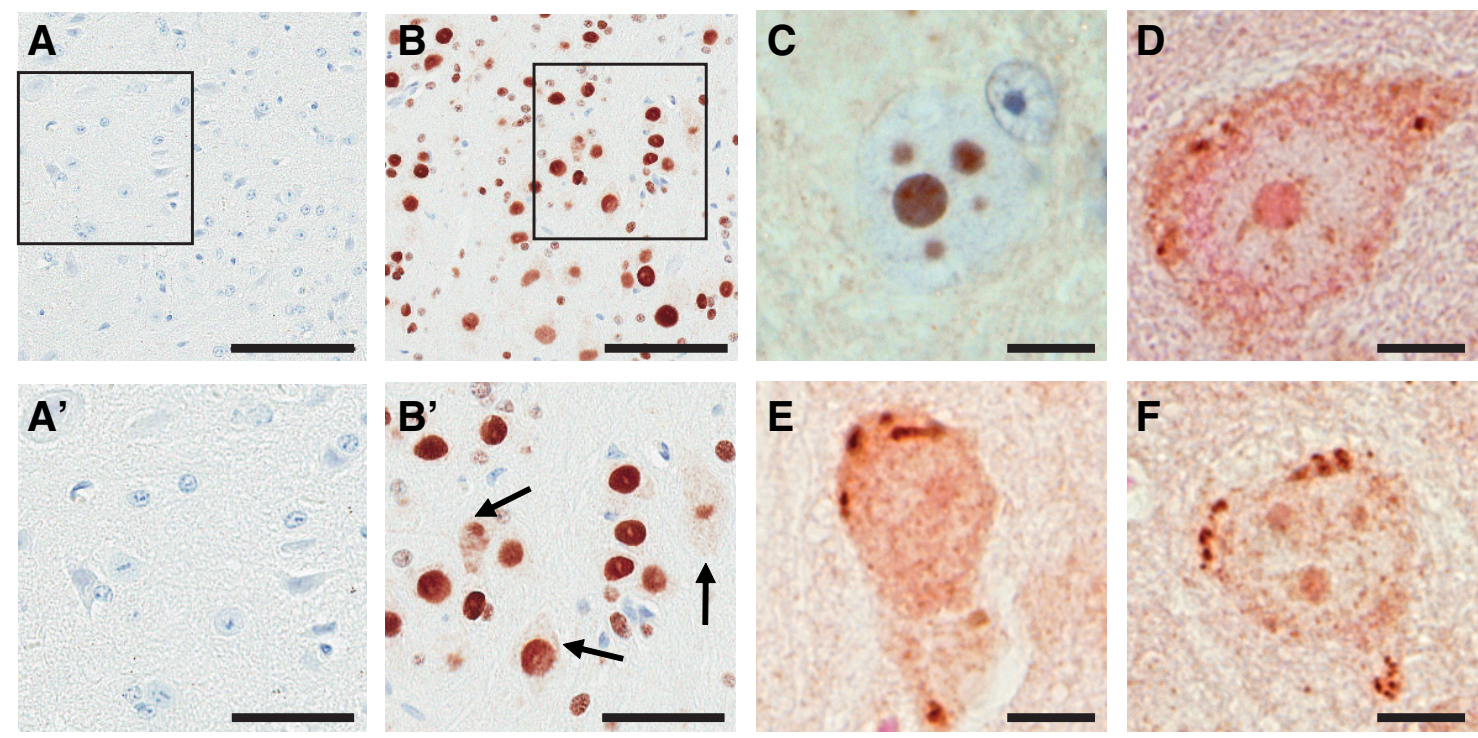

Figure 2. Neuropathology in TDP-43 ${ }_{\mathrm{PrP}}$ mice. $\boldsymbol{A}, \boldsymbol{B}$, Immunostaining in spinal cord sections of a 1-month old NT and symptomatic homozygous TDP-43 ${ }_{\mathrm{PrP}}$ mice using an antibody to $\mathrm{hTDP}-43$ shows hTDP-43 in nuclei of TDP-43 prp mice $\left(\boldsymbol{B}, \boldsymbol{B}^{\prime}\right)$, with occasional cytoplasmic staining (arrows). hTDP-43 was not observed in NT mice $\left(\boldsymbol{A}, \boldsymbol{A}^{\prime}\right)$. $\boldsymbol{C}-\boldsymbol{F}, \mathrm{IHC}$ analysis of spinal cord $(\boldsymbol{C}-\boldsymbol{E})$ or cortical $(\boldsymbol{F})$ neurons using an antibody for the detection of TDP-43 phosphorylated at serines 403/404 and hematoxylin $(\boldsymbol{C})$ or eosin $(\boldsymbol{D}-\boldsymbol{F})$ counterstain. Shown in $\boldsymbol{C}$ are nuclear bodies immunoreactive for pTDP-43 within a spinal cord motor neuron, while cytoplasmic pTDP-43-immunoreactive inclusions are shown in $\boldsymbol{D}-\boldsymbol{F}$. Scale bars: $\boldsymbol{A}, \boldsymbol{B}, 100 \mu \mathrm{m} ; \boldsymbol{A}^{\prime}, \boldsymbol{B}^{\prime}, 50 \mu \mathrm{m} ; \boldsymbol{C}-\boldsymbol{F}, 10 \mu \mathrm{m}$.

mTDP-43 mRNA levels were decreased by $64 \%(p<0.001, n=$ 3) for homozygous mice and by $49 \%(p<0.001, n=3)$ for hemizygous mice, compared to NT mice. This reduction was transgene dose dependent (supplemental Fig. $1 D$, available at www.jneurosci.org as supplemental material). These results suggest that, as hTDP-43 mRNA levels increase, mTDP-43 levels concomitantly decrease. This decrease in mTDP- 43 mRNA could explain why homozygous mice express $76 \%$ more hTDP-43 protein in brain lysates than hemizygous mice, but show only a $31 \%$ increase in total TDP-43 protein expression (mouse and human TDP-43) compared to hemizygotes.

Aged hemizygous TDP- 43 PrP mice are phenotypically, histologically, and immunohistochemically indistinguishable from aged NT controls. Given this, unless otherwise indicated, homozygous TDP- $43_{\mathrm{PrP}}$ mice will hereafter be referred to as TDP$43_{\mathrm{PrP}}$ mice. The body weight of TDP- $43_{\mathrm{PrP}}$ mice was reduced compared to NT mice from $14 \mathrm{~d}$ onward $(p<0.05)$ (Fig. $1 D$ ). While brain weight from TDP- $43_{\mathrm{PrP}}$ mice was significantly lower than age-matched controls at 1 month of age $(p<0.001)$ (Fig. $1 E)$, there was no evidence of muscle atrophy, as assessed by hematoxylin and eosin staining of gastrocnemius muscle sections from NT and TDP- $43_{\mathrm{PrP}}$ mice (data not shown). By $21 \mathrm{~d}$, TDP$43_{\mathrm{PrP}}$ mice had body tremors, difficulty walking faster than 10 $\mathrm{cm} / \mathrm{s}$ and recruiting their hindlimbs (supplemental Movie 1, available at www.jneurosci.org as supplemental material). They developed an aberrant "swimming" gait, which was absent in NT mice (supplemental Movie 2, available at www.jneurosci.org as supplemental material). In contrast to NT mice, TDP- $43_{\mathrm{PrP}}$ mice failed to show proper escape extension by splaying their hindlimbs upon elevation (Fig. $1 F, G$ ). Between 1 and 2 months of age, symptomatic TDP- $43_{\operatorname{PrP}}$ mice were unable to right themselves, became moribund, and required euthanasia.

\section{Truncated TDP- 43 products in TDP- $43_{\mathrm{PrP}}$ mice}

Biochemically, ALS and FTLD-U are characterized by the generation of $\sim 25 \mathrm{kDa}$ C-terminal fragments of TDP-43, which may play a role in TDP-43-mediated toxicity (Johnson et al., 2008; Zhang et al., 2009). Similar TDP-43 fragments were present in both hemizygous and homozygous TDP- $43_{\operatorname{PrP}}$ mice in brain (data not shown) and spinal cord fractions (Fig. $1 H$ ), with the quantity correlating with level of transgene expression. Note that these fragments had a comparable molecular weight to hTDP-43 from human neuroglioma cells following staurosporine-induced caspase activation (Fig. $1 \mathrm{H}$ ). We and others have shown that TDP-43 is cleaved into $\sim 25$ and $\sim 35 \mathrm{kDa}$ fragments upon caspase activation in cultured cells (Zhang et al., 2007; Dormann et al., 2009).

To examine the solubility of hTDP-43, brains from 1-monthold TDP- $43_{\text {PrP }}$ mice presenting with motor dysfunction and NT mice were subjected to sequential extraction with buffers of increasing strength, and fractions were studied by Western blotting. Immunoblotting using the human-specific TDP-43 antibody, which detects amino acids 205-222 of TDP-43 (Zhang et al., 2008), revealed that full-length hTDP-43 was present in all fractions from TDP- $43_{\mathrm{PrP}}$ mice (supplemental Fig. $1 E$, available at www.jneurosci.org as supplemental material), as it is in brain and spinal cord tissue from ALS and FTLD-U cases (Neumann et al., 2006; Zhang et al., 2007). Note that a considerably greater amount of TDP- 43 was present in the urea fraction of TDP- $43_{\operatorname{PrP}}$ mice compared to NT mice. The urea-soluble fraction of TDP$43_{\mathrm{PrP}}$ mice also contained TDP-43 fragments that were immunopositive for the C-terminal TDP-43 antibody.

\section{Phosphorylated TDP-43 neuronal inclusions in TDP- $43_{\text {PrP }}$ mice}

In the brains and spinal cords of TDP- $43_{\mathrm{PrP}}$ mice, hTDP- 43 was largely localized to neuronal nuclei (Fig. $2 B, B^{\prime}$ ). Aberrant distribution of cytoplasmic hTDP-43, without necessarily showing decreased nuclear hTDP-43 immunoreactivity, was occasionally detected in some neurons in the brainstem and spinal cord using a phosphorylation-independent TDP-43 antibody (Fig. $2 B, B^{\prime}$ ). Of particular interest, when IHC was performed using a phosphorylation-dependent (pS403/pS404) TDP-43 antibody (pTDP-43), $\sim 15 \%$ of the motor neurons in the anterior horn contained large TDP-43-immunoreactive nuclear bodies (Fig. $2 C$, Table 1). Cytoplasmic inclusions that were immunopositive 
Table 1. Regional distribution of COX-IV- and pTDP-43-immunoreactive aggregates

\begin{tabular}{llll}
\hline & COX-IV & Nuclear pTDP-43 & Cytoplasmic pTDP-43 \\
\hline Cortex, layer V & + & - & + \\
Hippocampus & - & - & - \\
Striatum & - & - & - \\
Brainstem & + & + - & + \\
Cerebellum & - & - & - \\
Anterior horn of spinal cord & ++ & ++ & ++ \\
Posterior horn of spinal cord & + & + & + \\
\hline
\end{tabular}

for pTDP-43 were also observed within the anterior horn of the spinal cord, although less frequently than nuclear bodies (Figs. $2 D, E, 3 G)$. Multiple cytoplasmic inclusions were often observed within a single neuron. In some cases, both nuclear and cytoplasmic pTDP-43 staining was present within the same cell. Compared to the anterior horn, far fewer aggregates of phosphorylated TDP-43 were present in the posterior horn (Table 1). Within neurons in layer $\mathrm{V}$ of the cortex, small distinct cytoplasmic inclusions immunoreactive for pTDP-43 were frequently observed (Fig. $2 F$ ). Such aggregates were less frequent ( $<5$ neurons/section) in the brainstem, and pTDP-43-immunoreactive nuclear bodies were not detected in the brain (Table 1).

\section{Neuronal cytoplasmic eosinophilic aggregates in spinal motor neurons of TDP-43 $3_{\text {PrP }}$ mice}

For the most part, the histology of the brain and spinal cord was similar between TDP- $43_{\operatorname{PrP}}$ mice and NT mice. A striking exception was the presence of cytoplasmic eosinophilic aggregates in spinal motor neurons (Fig. $3 F$ ) of TDP- $43_{\operatorname{PrP}}$ mice, especially in those animals with motor deficits. In the anterior horn of the spinal cord of TDP- $43_{\mathrm{PrP}}$ mice, $\sim 10 \%$ of neurons had eosinophilic aggregates, while fewer neurons in the posterior horn and brainstem were affected. In the brainstem, the eosinophilic aggregates were found mostly within the pontine nuclei and the midbrain tegmentum, including the red nucleus. To determine whether neurons with eosinophilic aggregates also had abnormal pTDP-43 immunoreactivity, pTDP-43 IHC was performed on spinal cord sections counterstained with eosin. Despite the fact that the relatively large size of eosinophilic aggregates compared to smaller cytoplasmic pTDP-43 inclusions made it difficult to conclusively determine if all neurons with eosinophilic aggregates had pTDP-43 inclusions, it was observed that the vast majority of neurons with eosinophilic aggregates also had abnormal pTDP-43immunoreactive punctate cytoplasmic inclusions (Fig. 3G) and, less often, pTDP-43-immunoreactive nuclear bodies. Though infrequent, some neurons $(\sim 1$ neuron/section) with eosinophilic aggregates only showed pTDP-43 immunostaining of nuclear bodies with no pTDP-43 cytoplasmic inclusion. The cytoplasmic pTDP-43 inclusions generally appeared to align along the periphery of the eosinophilic aggregate, though weak hTDP-43 immunoreactivity with a phosphorylation-independent TDP-43 antibody was sometimes observed within the eosinophilic aggregates (data not shown). Neuronal cytoplasmic pTDP-43 inclusions in the anterior horn were also found in the absence of eosinophilic aggregates or with very small eosinophilic aggregates, which may represent initial formation of the larger structures.

\footnotetext{
Abnormal levels of ubiquitination in TDP- $43_{\operatorname{PrP}}$ mice

In addition to eosinophilic aggregates and aberrant cytoplasmic and nuclear accumulation of phosphorylated TDP-43, TDP$43_{\operatorname{PrP}}$ mice displayed increased ubiquitination within the nucleus and cytoplasm of neurons in the anterior and posterior horns of
}

the spinal cord (Fig. $3 H$ ), thalamus, midbrain, and pons. Ubiquitination in TDP- $43_{\mathrm{PrP}}$ mice was more widespread than eosinophilic aggregates, and it did not specifically colocalize with the cytoplasmic or nuclear TDP-43 inclusions. Immunofluorescence staining of TDP- $43_{\mathrm{PrP}}$ mice spinal cord sections for ubiquitin and hTDP-43 did show some colocalization, but this was not always the case (supplemental Fig. $2 \mathrm{~A}$, available at www.jneurosci.org as supplemental material). To definitively determine if hTDP-43 is ubiquitinated in TDP- $43_{\operatorname{PrP}}$ mice, coimmunoprecipitation studies were done. Consistent with IHC, a marked increase in ubiquitin was observed in the brain of TDP- $43_{\mathrm{PrP}}$ mice by Western blotting (supplemental Fig. $2 B$, available at www.jneurosci.org as supplemental material); however, immunoprecipitated hTDP-43 was not immunopositive for ubiquitin, indicating that hTDP-43 was not itself ubiquitinated (supplemental Fig. 2, available at www. jneurosci.org as supplemental material).

\section{Axonal degeneration in TDP-43 $3_{\mathrm{PrP}}$ mice}

Neuronal loss via apoptosis was not detected in spinal cords of the TDP $-43_{\operatorname{PrP}}$ mice, as assessed by TUNEL staining and staining for activated caspase 3 (data not shown). Nevertheless, reactive gliosis and axonal degeneration were observed. Activated IBA-1positive microglia were increased in the anterior horn of the spinal cord of TDP- $43_{\operatorname{PrP}}$ mice (Fig. $3 I$ ), but only sparse resting microglia were detected in NT mice (Fig. 3D). Neurons with eosinophilic aggregates did not have microglial satellitosis. Reactive GFAP-positive astrocytosis was present in the gray matter of the spinal cord of symptomatic TDP- $43_{\mathrm{PrP}}$ mice (Fig. $3 J$ ) but not in NT mice (Fig. 3E). Silver staining with a kit that detects degenerating neurons (Denayer et al., 2008) revealed degenerating neurites, axons, and neurons in the spinal cord of TDP $-43_{\operatorname{PrP}}$ mice (Fig. $4 B$ ), whereas only isolated beaded neurites were detected in NT mice (Fig. 4A). Vacuolization of myelin and the appearance of myelin ovoids, consistent with myelin degeneration accompanying axonal degeneration, were observed in LFB-PAS and toluidine blue stained sections of anterolateral funiculi of the spinal cord of symptomatic TDP- $43_{\operatorname{PrP}}$ mice (Fig. $4 C, D$ ).

\section{Motoneuron eosinophilic aggregates are composed of abnormal mitochondrial clusters}

The eosinophilic aggregates in spinal motor neurons of symptomatic TDP $-43_{\operatorname{PrP}}$ mice were composed of abnormal clusters of mitochondria, as confirmed at the electron microscopic level. The mitochondrial clusters sometimes displaced the nucleus (Fig. 5A), and many of the mitochondria had ultrastructural features suggestive of degeneration, with decreased cristae and vacuoles within the mitochondrial matrix (Fig. 5A, right inset). Similar abnormalities were observed in mitochondria in dendrites and axons (Fig. $5 B, D$ ) of spinal cord neurons of TDP- $43_{\mathrm{PrP}}$ mice. Degenerating mitochondria, as well as autophagic vacuoles, were also detected within swollen axons in the spinal cord white matter (Fig. 5C). IHC for COX-IV, a mitochondrial marker, revealed varying degrees of COX-IV-positive mitochondrial clusters in TDP-43 ${ }_{\text {PrP }}$ but not NT mice (Fig. 5J,L, Table 1; supplemental Fig. 3B, available at www. jneurosci.org as supplemental material). These COX-IV-positive clusters colocalized with eosinophilic aggregates in neurons of the spinal cord and brainstem (Fig. 5J,K). Furthermore, the COX-IVimmunopositive clusters stained blue with Luxol fast blue, consistent with the presence of high phospholipid content of mitochondria (Fig. 5L, M; supplemental Fig. 3C,D, available at www.jneurosci.org as supplemental material).

Mitochondria are dynamic organelles that constantly undergo fission and fusion, two processes that regulate mitochondria 

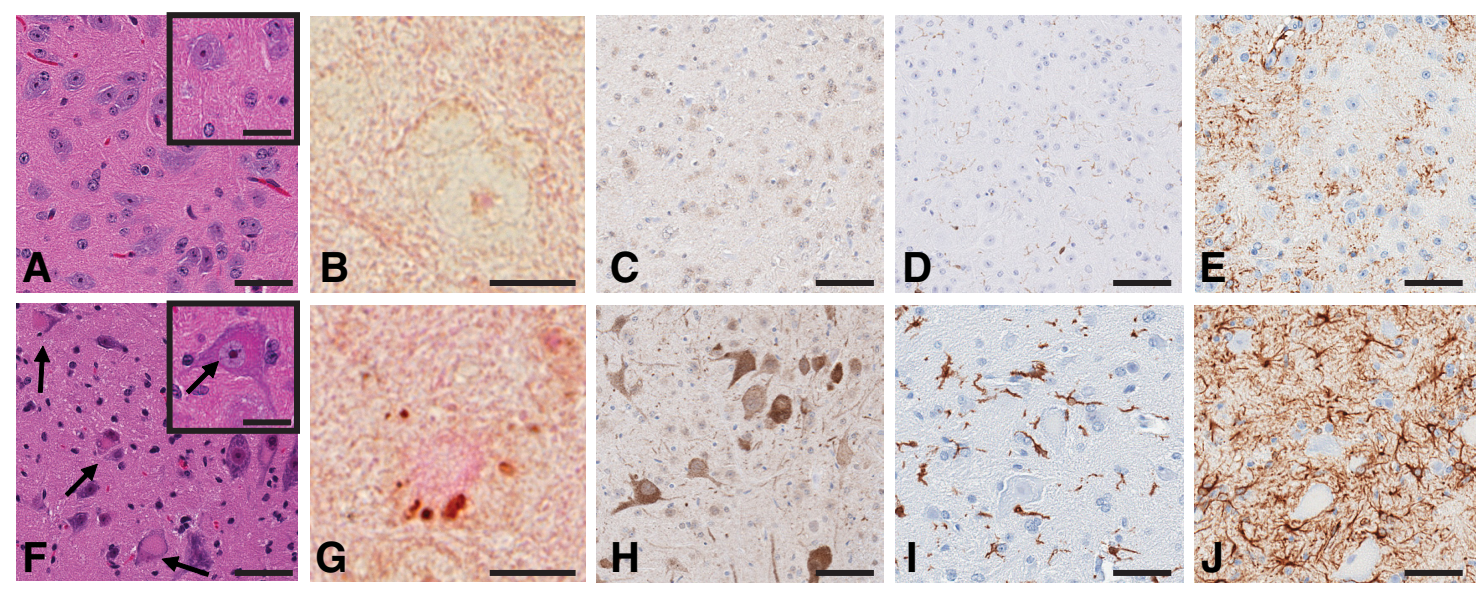

Figure 3. Neuropathology in TDP-43 $3_{\mathrm{PrP}}$ mice. $\boldsymbol{A}, \boldsymbol{F}$, Hematoxylin and eosin staining in spinal cord sections of 1-month-old NT and symptomatic homozygous TDP-43 ${ }_{\mathrm{PrP}}$ mice. Eosinophilic

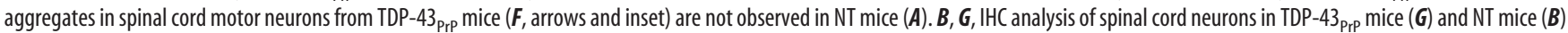
using an antibody for the detection of TDP-43 phosphorylated at serines $403 / 404$ and eosin counterstain. $\boldsymbol{C}, \boldsymbol{H}$, Abnormal ubiquitin immunoreactivity was present in the cytoplasm and nucleus of neurons in TDP-43 prp mice $(\boldsymbol{H})$ but not in NT mice $(\boldsymbol{C}$. Enhanced IBA-1 $(\boldsymbol{I}, \boldsymbol{D})$ and GFAP $(\boldsymbol{J}, \boldsymbol{E})$ immunoreactivity indicative of activated microglia and reactive astrogliosis, respectively, were observed in TDP-43 $3_{\text {rP }}(\boldsymbol{I}, \boldsymbol{J})$, but not NT mice $(\boldsymbol{D}, \boldsymbol{E})$. Scale bars: $\boldsymbol{A}, \boldsymbol{C}-\boldsymbol{F}, \boldsymbol{H}-\boldsymbol{J}, 50 \mu \mathrm{m} ; \boldsymbol{A}, \boldsymbol{F}$, insets, $25 \mu \mathrm{m} ; \boldsymbol{B}, \boldsymbol{G}, 10 \mu \mathrm{m}$.
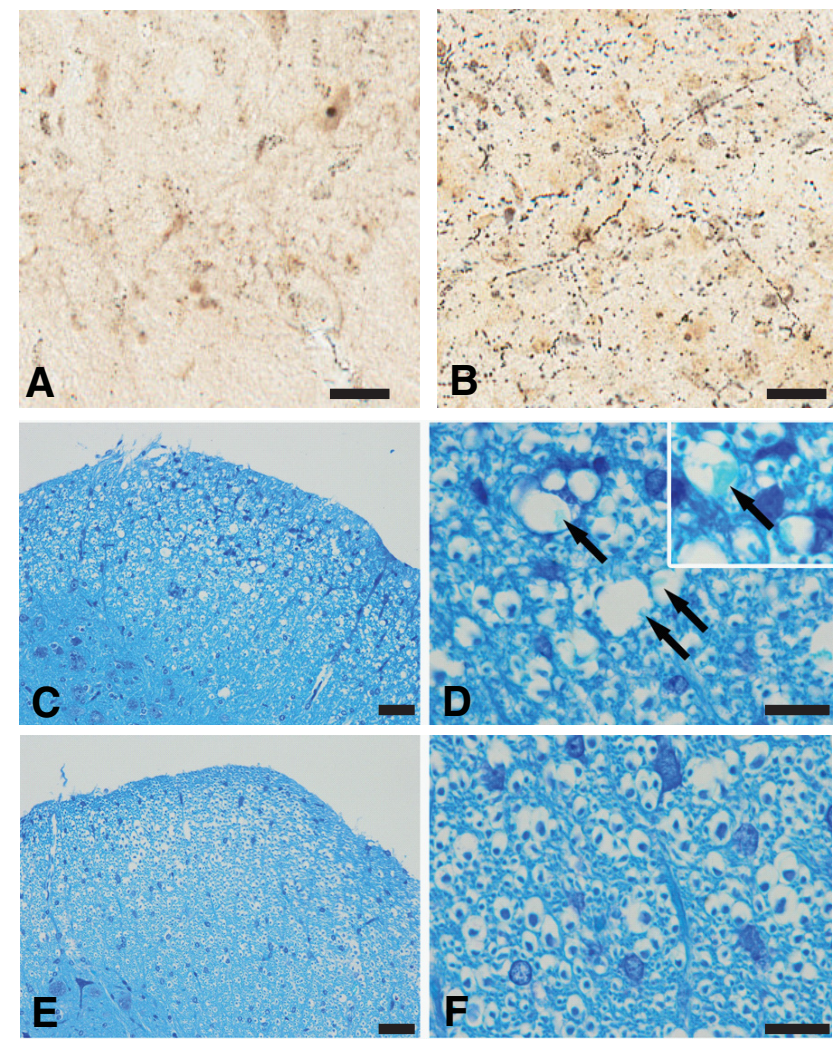

Figure 4. Axonal degeneration and myelin degeneration in TDP-43 $3_{\mathrm{PrP}}$ mice. Silver staining with a method specific for neurodegeneration of neurites and neuronal cell bodies revealed argyrophilic degenerating neurites and neurons in spinal cord of symptomatic TDP-43 ${ }_{\text {prp }}$ mice (B) compared to NT controls $(\boldsymbol{A})$. Toluidine blue stains show myelin vacuolization, with myelin ovoids (arrows and inset) in anterolateral funiculi of spinal cords of symptomatic TDP-43 $3_{\text {PrP }}$ mice $(\boldsymbol{C}, \boldsymbol{D})$ but not in NT mice $(\boldsymbol{E}, \boldsymbol{F})$. Scale bars: $\boldsymbol{A}, \boldsymbol{B}, 20 \mu \mathrm{m} ; \boldsymbol{C}, \boldsymbol{E}, 40 \mu \mathrm{m} ; \boldsymbol{D}, \boldsymbol{F}, 20 \mu \mathrm{m}$.

morphology, distribution, and function. Given the abnormal clustering of mitochondria observed in TDP- $43_{\operatorname{PrP}}$ mice, several components of the fusion and fission machinery (Chen and Chan, 2005) were examined in NT, hemizygous, and homozygous TDP-43 $3_{\text {PrP }}$ mice (Fig. 5E). As hTDP-43 levels increased, a concomitant decrease in mitofusin 1 , which plays an essential role in mitochondrial fusion, was observed. In contrast, expression of Fis1, a component of the fission machinery, was upregulated in TDP- $43_{\mathrm{PrP}}$ mice compared to NT mice, as were levels of phosphorylated DLP1, which is also involved in mitochondrial fission.

\section{Discussion}

We report on the generation and characterization of novel transgenic mice expressing wild-type hTDP-43. Given that the majority of ALS and FTLD-U cases with TDP-43 pathology are not associated with TARDBP mutations, it is essential to develop model systems that can be used to elucidate the normal function of wild-type TDP-43 in the CNS and to determine if wild-type TDP-43 can directly cause neurodegeneration. Wils et al. (2010) have recently reported their findings regarding transgenic mouse lines overexpressing wild-type hTDP-43 under the control of a neuronal murine Thy-1 promoter (referred to here as TDP$43_{\text {mThy-1 }}$ mice). The comparison of abnormalities among models of TDP-43 proteinopathies will provide insight on the mechanisms underlying TDP-43-induced neurotoxicity. In a similar fashion, mice expressing wild-type TDP-43 will serve as a crucial control when assessing how mutations in TDP-43 contribute to neurodegeneration. Indeed, mice expressing mutant A315T hTDP-43 under the same PrP promoter used in the present study have been previously described (Wegorzewska et al., 2009); however, since a control wild-type hTDP-43 line was not included in that study, it is difficult to definitively ascribe the phenotype of Prp-TDP43 ${ }^{\mathrm{A} 315 \mathrm{~T}}$ mice to mutant TDP-43 rather than to TDP-43 overexpression in general. For instance, a number of features are shared between Prp-TDP43 ${ }^{\text {A315T }}$ mice and the wild-type TDP$43_{\mathrm{PrP}}$ mice characterized in the present study, including reduced body and brain weights, decreased righting and escape extension, and an impaired "swimming" gait. In these two transgenic mouse lines, hTDP-43 expression was observed in neurons of the brain and spinal cord. Additionally, both soluble and insoluble fulllength TDP-43, as well as TDP-43 truncation products of $\sim 25$ and $35 \mathrm{kDa}$, were present, as also observed in TDP- $43_{\mathrm{mThy}-1}$ mice (Wegorzewska et al., 2009; Wils et al., 2010). hTDP-43 expression in our wild-type TDP- $43_{\operatorname{PrP}}$ mice was approximately equivalent to that in Prp-TDP43 ${ }^{\mathrm{A} 315 \mathrm{~T}}$ mice, with both elevated $\sim 2.5-3$-fold above endogenous levels. Importantly, we found that mTDP-43 

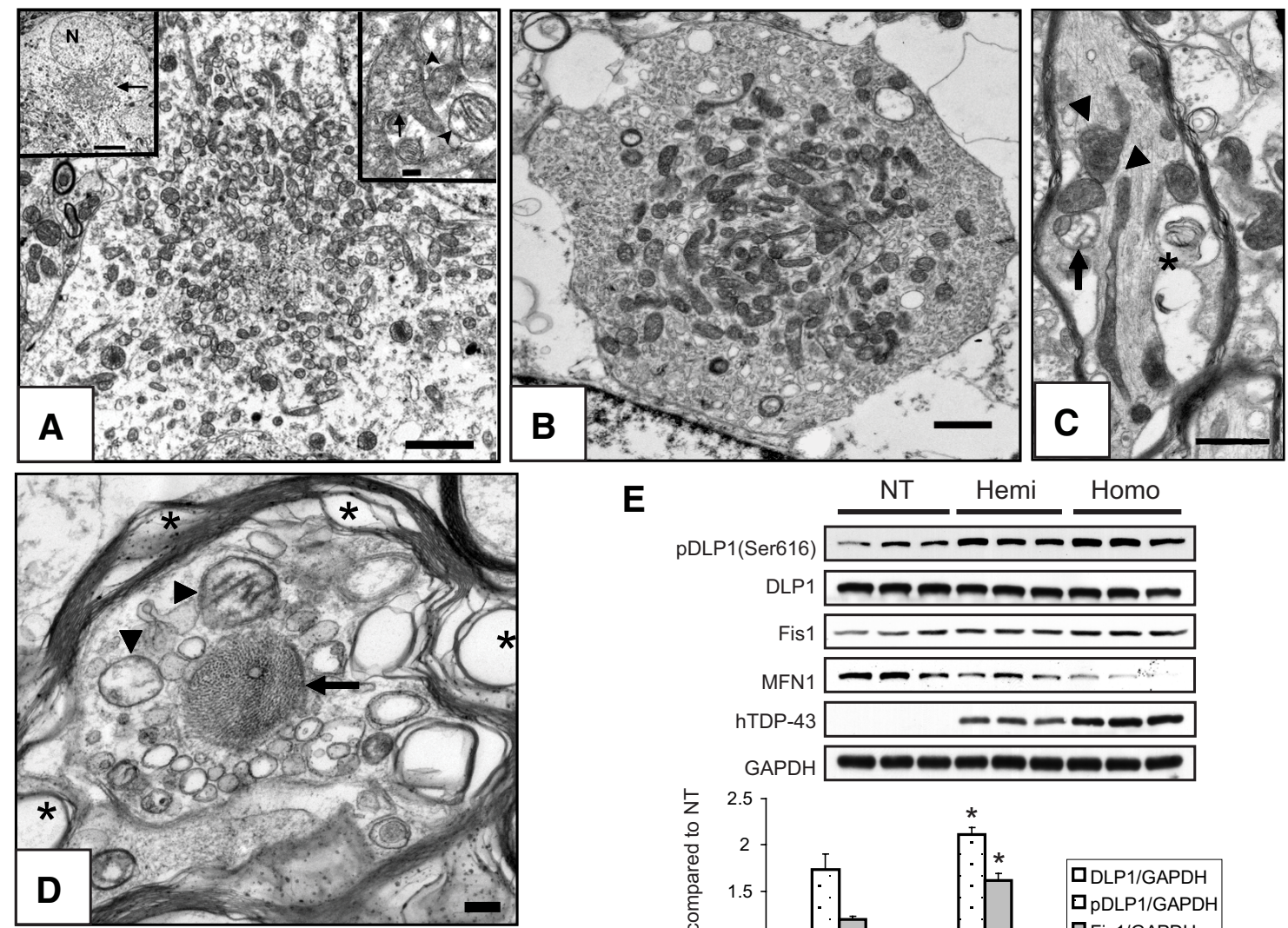

E
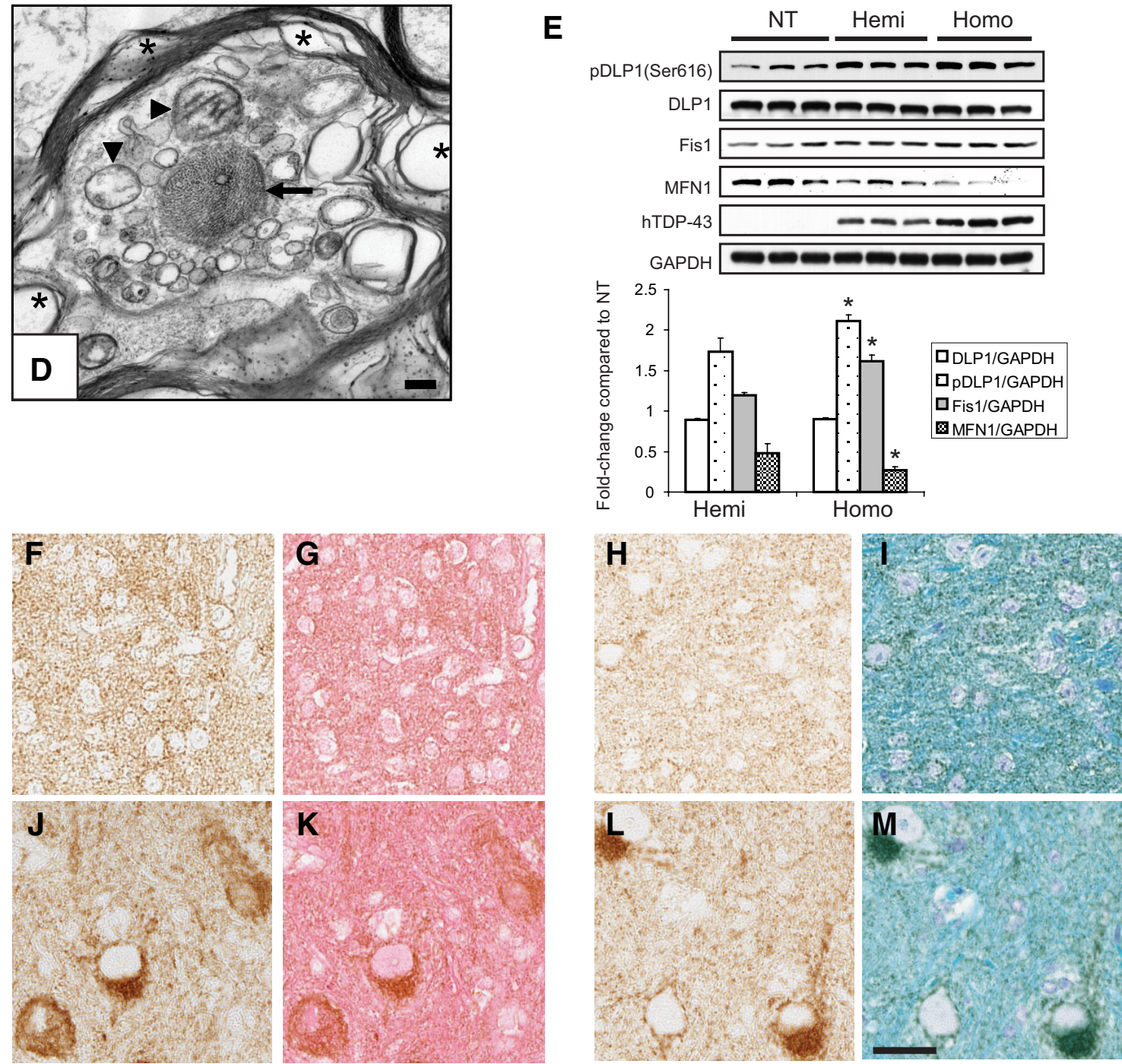

Figure 5. Ultrastructural evidence of abnormal aggregation of mitochondria in homozygous TDP-43 $3_{\text {prp }}$ mice. The upper left inset of $A$ depicts a low-power image of a motor neuron in the anterior horn of a 1-month old symptomatic homozygous TDP-43 $3_{\text {rP }}$ mouse containing a cytoplasmic aggregate (arrow) and a peripherally located nucleus ( $N$; $s$ cale bar, $5 \mu \mathrm{m}$ ). Enlargement of the aggregate (panel $\boldsymbol{A}$, proper) reveals clustered mitochondria (scale bar, $2 \mu \mathrm{m}$ ). A large, abnormal mitochondrion with disorganized inner cristae (arrow) is shown in the right upper inset. Also observed are mitochondria with paucity of cristae and vacuoles within the mitochondrial matrix (arrowheads; scale bar, $0.2 \mu \mathrm{m}$ ). $\boldsymbol{B}$, The accumulation of mitochondria of various shapes and sizes and of small and large vesicles is observed in a swollen dendrite (scale bar, $1 \mu \mathrm{m}$ ). C, Abnormally shaped (arrowheads) and degenerated (arrow) mitochondria, as well as autophagic vacuoles (*) are present within a swollen axon of a spinal cord neuron (scale bar, $0.25 \mu \mathrm{m})$. D, An axon with a vacuolated myelin sheath $\left({ }^{*}\right)$, containing degenerating mitochondria (arrowheads), many vesicles/vacuoles, and tightly packed neurofilaments (arrow) is shown (scale bar, $2 \mu \mathrm{m}$ ). $E$, Immunoblot analysis of mitofusin 1 (MFN1), Fis1, DLP1, and Ser616-phosphorylated DLP1 expression in brain lysates of nontransgenic, hemizygous, and homozygous TDP-43 $3_{\text {rp }}$ mice. Densitometric analysis of Western blots is shown. While total DLP1 levels did not change, phosphorylation of DLP1 at Ser616 was

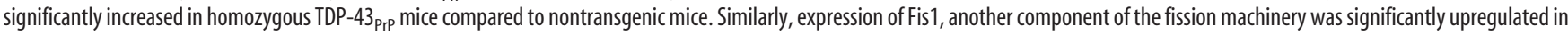
TDP-43 $3_{\mathrm{prp}}$ mice. In contrast, mitofusin 1 (MFN1) expression was significantly decreased in TDP-43 prp $_{\text {mice. }}{ }^{*} p<0.05$ compared to levels in nontransgenic mice, as assessed by one-way AN0VA ( $n=$ 3). hemi, Hemizygous; homo, homozygous. $\boldsymbol{F}, \boldsymbol{J}$, Following IHC against the mitochondrial marker, COX-IV, spinal cord sections were counterstained with eosin $(\boldsymbol{G}, \boldsymbol{K})$. Notice the COX-IV-positive aggregates, which are also eosinophilic, in TDP-43 $3_{\text {prp }}$ mice $(\boldsymbol{J}, \boldsymbol{K})$ but NT mice $(\boldsymbol{F}, \boldsymbol{G})$. Likewise, COX-IV-positive aggregates $(\boldsymbol{L})$ stained blue following staining with toluidine blue $(\boldsymbol{M})$ in TDP-43 $3_{\mathrm{PrP}}$ mice, supporting the presence of high phospholipid levels associated with mitochondria. No similar staining was observed in NT mice (H,I). Scale bar, $24 \mu \mathrm{m}$. 
is downregulated in response to hTDP-43 overexpression in TDP $-43_{\text {PrP }}$ mice, suggesting that a compensatory mechanism exists to tightly control levels of TDP-43 expression.

As reported in Prp-TDP43 ${ }^{\mathrm{A} 315 \mathrm{~T}}$ mice and TDP- $43_{\mathrm{mThy}-1}$ mice, hTDP-43 primarily localized to the nucleus in the wild-type TDP $-43_{\text {PrP }}$ mice. Occasionally, cytoplasmic distribution of hTDP-43 was detected in TDP- $43_{\operatorname{PrP}}$ mice by IHC using a phosphorylation-independent TDP-43 antibody, but unlike the abnormal redistribution of TDP-43 observed in human TDP-43 proteinopathies (Neumann et al., 2006), there was not necessarily a decrease in nuclear TDP-43 immunoreactivity. Interestingly, a number of the neurons with eosinophilic aggregates composed of abnormal clusters of mitochondria had decreased nuclear hTDP-43 immunoreactivity. Of note, IHC performed using a phosphorylation-dependent TDP-43 antibody revealed pS403/ pS404-TDP-43-positive abnormal nuclear bodies and punctate cytoplasmic inclusions in neurons of the spinal cord and brain. Similar to the findings in our wild-type TDP- $43_{\operatorname{PrP}}$ mice, aggregates composed of phosphorylated TDP-43 were also observed in TDP- $43_{\text {mThy-1 }}$ mice using an antibody specific to pS409/pS410TDP-43 (Wegorzewska et al., 2009; Wils et al., 2010). While TDP-43 phosphorylation was not reported in Prp-TDP43 ${ }^{\mathrm{A} 315 \mathrm{~T}}$ mice (Wegorzewska et al., 2009), it is unclear whether the phosphorylation status of TDP-43 was investigated in this model.

In addition to the accumulation of phosphorylated TDP-43, two features were prominent within neurons of wild-type TDP$43_{\operatorname{PrP}}$ mice: (1) the accumulation of cytosolic and nuclear ubiquitin, and (2) the formation of eosinophilic inclusions composed of abnormal aggregates of mitochondria. Consistent with results from PrP-TDP43 ${ }^{\mathrm{A} 315 \mathrm{~T}}$ mice (Wegorzewska et al., 2009), elevated levels of ubiquitin in TDP- $43_{\operatorname{PrP}}$ mice were not caused by accumulation of ubiquitinated hTDP-43. Similarly, while Wils et al. (2010) observed ubiquitin-positive aggregates in TDP- $43_{\text {mThy- }}$ mice, TDP-43 was not the major ubiquitinated protein in many of the inclusions. Although TDP-43 ubiquitination is reported in ALS and FTLD-U (Neumann et al., 2006), this has met with some controversy. Data from three-dimensional deconvolution imaging suggest that TDP-43 need not be ubiquitinated to form inclusions and that TDP-43 may wrap around preexisting ubiquitinated cores (Sanelli et al., 2007). Due to the early lethality of TDP-43 $3_{\operatorname{PrP}}$ mice, it is not known if hTDP-43 might have eventually aggregated around cytoplasmic ubiquitin. The substrate for abnormal ubiquitination in these models remains to be determined. Regardless, it is clear that TDP-43 overexpression leads to the cytoplasmic accumulation of ubiquitin, as observed by others and by us (Wegorzewska et al., 2009; Wils et al., 2010).

Perhaps the most exciting discovery from the characterization of our TDP- $43_{\text {PrP }}$ mice is that hTDP-43 expression results in the abnormal clustering of mitochondria within neurons. Importantly, Wegorzewska et al. (2009) also described "amorphous aggregates" that appeared eosinophilic in the spinal cord of PrPTDP43 ${ }^{\mathrm{A} 315 \mathrm{~T}}$ mice, yet the nature of this abnormality was not explored. The mechanism underlying the formation of mitochondrial clusters in the wild-type TDP- $43_{\mathrm{PrP}}$ mice is not understood. Given the primarily nuclear localization of hTDP-43 in TDP $-43_{\text {PrP }}$ mice, it is likely that aberrations in nuclear TDP-43 functions underlie the mitochondrial abnormalities, as opposed to a direct association of TDP-43 with mitochondria. For instance, TDP-43 overexpression may alter the splicing or translation of crucial mediators of axonal transport. The presence of axonal degeneration in spinal cord neurons, together with perinuclear clusters of mitochondria in TDP- $43_{\operatorname{PrP}}$ mice, suggests that axonal transport deficits may be involved. Altered mito- chondrial trafficking and mitochondrial disruption in association with proteins linked to neurodegenerative disease is not without precedent (Vives-Bauza et al., 2010). Alternatively, TDP-43 overexpression may lead to the misregulation of mitochondria fission or fusion, as this has also been shown to cause abnormal perinuclear clustering of mitochondria (Baloh et al., 2007; Huang et al., 2007; Wang et al., 2008). Indeed, we have found that the expression of key proteins in the regulation of mitochondrial fission and fusion are abnormally expressed or regulated. While the exact mechanisms underlying mitochondrial abnormalities in TDP- $43_{\operatorname{PrP}}$ mice remain to be deciphered, TDP-43 truncation and the accumulation of phosphorylated TDP-43 may play a role. Phosphorylated and truncated TDP-43, as well as mitochondrial clusters were observed in the spinal cord. In the brain, however, TDP-43 truncation products and phosphorylated TDP-43 inclusions were observed but only rarely were eosinophilic aggregates observed. This could suggest that TDP-43 truncation and phosphorylation precede the formation of mitochondrial clusters. It is, however, possible that the consequences of hTDP-43 expression are dependent upon the region and cellular context in which it is expressed, such that hTDP-43 in the brain, unlike the spinal cord, may not cause mitochondrial clustering. Alternatively, mitochondrial clustering and the posttranslation modification of TDP-43 may be parallel processes that do not directly influence the occurrence of the other.

It is noteworthy that abnormal mitochondria accumulate in presynaptic axosomatic terminals of motor neurons in ALS (Sasaki and Iwata, 1999) and that cytoplasmic granules in motor neurons contain mitochondria with TDP-43 immunoreactivity (Mori et al., 2008). Also of interest is the observation that mutant $\mathrm{Cu} / \mathrm{Zn}$ superoxide dismutase (SOD1) is associated with aberrant spinal motor neuron mitochondria in humans and rodents with ALS due to SOD1 mutations, and that mitochondrial clusters are present in motor axons of mutant SOD1 transgenic rats (SoteloSilveira et al., 2009). Together, these findings implicate mitochondrial abnormalities in TDP-43-induced toxicity and provide a potential convergence between TDP-43 and SOD1 in the pathogenesis of ALS.

Collectively, our data indicate that moderate overexpression of hTDP-43 can downregulate endogenous TDP-43 and cause TDP-43 truncation and the formation of aggregates of phosphorylated TDP-43 and eventually to elevated levels of cytoplasmic and nuclear ubiquitin, axonal degeneration, reactive gliosis, gait abnormalities, and early lethality. We also show strong evidence indicating that overexpression of hTDP-43 plays a critical role in mitochondrial dynamics. Importantly, these effects are not due to a mutant-specific mechanism. Overall, TDP- $43_{\mathrm{PrP}}$ mice will be a valuable tool in understanding the normal role of hTDP-43 and will provide an essential resource to dissect the pathogenic mechanisms between wild-type and mutant hTDP-43.

\section{References}

Arai T, Hasegawa M, Akiyama H, Ikeda K, Nonaka T, Mori H, Mann D, Tsuchiya K, Yoshida M, Hashizume Y, Oda T (2006) TDP-43 is a component of ubiquitin-positive tau-negative inclusions in frontotemporal lobar degeneration and amyotrophic lateral sclerosis. Biochem Biophys Res Commun 351:602-611.

Baloh RH, Schmidt RE, Pestronk A, Milbrandt J (2007) Altered axonal mitochondrial transport in the pathogenesis of Charcot-Marie-Tooth disease from mitofusin 2 mutations. J Neurosci 27:422-430.

Borchelt DR, Davis J, Fischer M, Lee MK, Slunt HH, Ratovitsky T, Regard J, Copeland NG, Jenkins NA, Sisodia SS, Price DL (1996) A vector for expressing foreign genes in the brains and hearts of transgenic mice. Genet Anal 13:159-163. 
Chen H, Chan DC (2005) Emerging functions of mammalian mitochondrial fusion and fission. Hum Mol Genet 14 Spec No 2:R283-R289.

Denayer E, Ahmed T, Brems H, Van Woerden G, Borgesius NZ, CallaertsVegh Z, Yoshimura A, Hartmann D, Elgersma Y, D’Hooge R, Legius E, Balschun D (2008) Spred1 is required for synaptic plasticity and hippocampus-dependent learning. J Neurosci 28:14443-14449.

Dormann D, Capell A, Carlson AM, Shankaran SS, Rodde R, Neumann M, Kremmer E, Matsuwaki T, Yamanouchi K, Nishihara M, Haass C (2009) Proteolytic processing of TAR DNA binding protein- 43 by caspases produces $\mathrm{C}$-terminal fragments with disease defining properties independent of progranulin. J Neurochem 110:1082-1094.

Gitcho MA, Baloh RH, Chakraverty S, Mayo K, Norton JB, Levitch D, Hatanpaa KJ, White CL 3rd, Bigio EH, Caselli R, Baker M, Al-Lozi MT, Morris JC, Pestronk A, Rademakers R, Goate AM, Cairns NJ (2008) TDP-43 A315T mutation in familial motor neuron disease. Ann Neurol 63: $535-538$.

Hasegawa M, Arai T, Nonaka T, Kametani F, Yoshida M, Hashizume Y, Beach TG, Buratti E, Baralle F, Morita M, Nakano I, Oda T, Tsuchiya K, Akiyama H (2008) Phosphorylated TDP-43 in frontotemporal lobar degeneration and amyotrophic lateral sclerosis. Ann Neurol 64:60-70.

Huang P, Yu T, Yoon Y (2007) Mitochondrial clustering induced by overexpression of the mitochondrial fusion protein Mfn2 causes mitochondrial dysfunction and cell death. Eur J Cell Biol 86:289-302.

Johnson BS, McCaffery JM, Lindquist S, Gitler AD (2008) A yeast TDP-43 proteinopathy model: exploring the molecular determinants of TDP-43 aggregation and cellular toxicity. Proc Natl Acad Sci U S A 105: 6439-6444.

Kabashi E, Valdmanis PN, Dion P, Spiegelman D, McConkey BJ, Vande Velde C, Bouchard JP, Lacomblez L, Pochigaeva K, Salachas F, Pradat PF, Camu W, Meininger V, Dupre N, Rouleau GA (2008) TARDBP mutations in individuals with sporadic and familial amyotrophic lateral sclerosis. Nat Genet 40:572-574.

Lin WL, Zehr C, Lewis J, Hutton M, Yen SH, Dickson DW (2005) Progressive white matter pathology in the spinal cord of transgenic mice expressing mutant (P301L) human tau. J Neurocytol 34:397-410.

Mori F, Tanji K, Zhang HX, Nishihira Y, Tan CF, Takahashi H, Wakabayashi K (2008) Maturation process of TDP-43-positive neuronal cytoplasmic inclusions in amyotrophic lateral sclerosis with and without dementia. Acta Neuropathol 116:193-203.

Neumann M, Sampathu DM, Kwong LK, Truax AC, Micsenyi MC, Chou TT, Bruce J, Schuck T, Grossman M, Clark CM, McCluskey LF, Miller BL, Masliah E, Mackenzie IR, Feldman H, Feiden W, Kretzschmar HA, Trojanowski JQ, Lee VM (2006) Ubiquitinated TDP-43 in frontotemporal lobar degeneration and amyotrophic lateral sclerosis. Science 314:130-133.

Neumann M, Kwong LK, Lee EB, Kremmer E, Flatley A, Xu Y, Forman MS, Troost D, Kretzschmar HA, Trojanowski JQ, Lee VM (2009) Phosphorylation of S409/410 of TDP-43 is a consistent feature in all sporadic and familial forms of TDP-43 proteinopathies. Acta Neuropathol 117:137-149.

Rutherford NJ, Zhang YJ, Baker M, Gass JM, Finch NA, Xu YF, Stewart H, Kelley BJ, Kuntz K, Crook RJ, Sreedharan J, Vance C, Sorenson E, Lippa C, Bigio EH, Geschwind DH, Knopman DS, Mitsumoto H, Petersen RC,
Cashman NR, et al. (2008) Novel mutations in TARDBP (TDP-43) in patients with familial amyotrophic lateral sclerosis. PLoS Genet 4:e1000193.

Sanelli T, Xiao S, Horne P, Bilbao J, Zinman L, Robertson J (2007) Evidence that TDP-43 is not the major ubiquitinated target within the pathological inclusions of amyotrophic lateral sclerosis. J Neuropathol Exp Neurol 66:1147-1153.

Sasaki S, Iwata M (1999) Ultrastructural change of synapses of Betz cells in patients with amyotrophic lateral sclerosis. Neurosci Lett 268:29-32.

Sotelo-Silveira JR, Lepanto P, Elizondo V, Horjales S, Palacios F, MartinezPalma L, Marin M, Beckman JS, Barbeito L (2009) Axonal mitochondrial clusters containing mutant SOD1 in transgenic models of ALS. Antioxid Redox Signal 11:1535-1545.

Sreedharan J, Blair IP, Tripathi VB, Hu X, Vance C, Rogelj B, Ackerley S, Durnall JC, Williams KL, Buratti E, Baralle F, de Belleroche J, Mitchell JD, Leigh PN, Al-Chalabi A, Miller CC, Nicholson G, Shaw CE (2008) TDP-43 mutations in familial and sporadic amyotrophic lateral sclerosis. Science 319:1668-1672.

Vives-Bauza C, Zhou C, Huang Y, Cui M, de Vries RL, Kim J, May J, Tocilescu MA, Liu W, Ko HS, Magrané J, Moore DJ, Dawson VL, Grailhe R, Dawson TM, Li C, Tieu K, Przedborski S (2010) PINK1-dependent recruitment of Parkin to mitochondria in mitophagy. Proc Natl Acad Sci U S A 107:378-383

Wang X, Su B, Fujioka H, Zhu X (2008) Dynamin-like protein 1 reduction underlies mitochondrial morphology and distribution abnormalities in fibroblasts from sporadic Alzheimer's disease patients. Am J Pathol 173:470-482.

Wegorzewska I, Bell S, Cairns NJ, Miller TM, Baloh RH (2009) TDP-43 mutant transgenic mice develop features of ALS and frontotemporal lobar degeneration. Proc Natl Acad Sci U S A 106:18809-18814.

Wils H, Kleinberger G, Janssens J, Pereson S, Joris G, Cuijt I, Smits V, Ceuterick-de Groote C, Van Broeckhoven C, Kumar-Singh S (2010) TDP-43 transgenic mice develop spastic paralysis and neuronal inclusions characteristic of ALS and frontotemporal lobar degeneration. Proc Natl Acad Sci U S A 107:3858-3863.

Yokoseki A, Shiga A, Tan CF, Tagawa A, Kaneko H, Koyama A, Eguchi H, Tsujino A, Ikeuchi T, Kakita A, Okamoto K, Nishizawa M, Takahashi H, Onodera O (2008) TDP-43 mutation in familial amyotrophic lateral sclerosis. Ann Neurol 63:538-542.

Zhang HX, Tanji K, Mori F, Wakabayashi K (2008) Epitope mapping of 2E2-D3, a monoclonal antibody directed against human TDP-43. Neurosci Lett 434:170-174.

Zhang YJ, Xu YF, Dickey CA, Buratti E, Baralle F, Bailey R, Pickering-Brown S, Dickson D, Petrucelli L (2007) Progranulin mediates caspasedependent cleavage of TAR DNA binding protein-43. J Neurosci 27:10530-10534.

Zhang YJ, Xu YF, Cook C, Gendron TF, Roettges P, Link CD, Lin WL, Tong J, Castanedes-Casey M, Ash P, Gass J, Rangachari V, Buratti E, Baralle F, Golde TE, Dickson DW, Petrucelli L (2009) Aberrant cleavage of TDP-43 enhances aggregation and cellular toxicity. Proc Natl Acad Sci U S A 106:7607-7612. 